\title{
LOKALNE ZRÓŻNICOWANIE PARAMETRÓW WIATRU NA MIERZEI ŁEBSKIEJ (SŁOWIŃSKI PARK NARODOWY)
}

\author{
EWA BEDNORZ, LESZEK KOLENDOWICZ
}

Zakład Klimatologii, Instytut Geografii Fizycznej i Kształtowania Środowiska Przyrodniczego, Uniwersytet im. Adama Mickiewicza

\begin{abstract}
The daily course of wind speed and direction over chosen active surfaces close to the sea shore on the Leba Bar have been analysed. Measurements took place in the vicinity of the field station of the Department of Climatology, Adam Mickiewicz University in the period from the 1st of July until 25th of August 2009. Two measurement posts, representing different morphological and plant zones were chosen: 1) the frontal dune, 2) coniferous forest, and additionally, the measurements from an automatic meteorological station, located at the grey dune in the topographic low behind the frontal dune, were used.

The daily cycle of wind speed changes, with its maximum in the early afternoon and minimum at night, was identified at both measurement posts. Wind speed decreases towards the land interior. The difference of a few hundred meters distance from the sea shore between posts 1 and 2 causes substantial decrease in wind speed. Additionally, the topography of the second post, which is located in the forest, in the depression behind the frontal dune, strongly reduces wind speed.

The breeze circulation was weak during the measurement period while the macroscale western circulation was dominant with shorter periods when the eastern flow dominated. The effect of the night breeze was expressed by southern deviation of wind direction and the daily breeze in the afternoon, whereas in the evening the northern directions dominated.
\end{abstract}

Keywords: Słowiński National Park, wind direction and speed

\section{WSTĘP}

Wiatr, czyli poziomy ruch powietrza generowany jest przez różnice ciśnienia atmosferycznego, które z kolei wynikają w dużym stopniu z termiki powietrza. Zasada ta obowiązuje tak w skali makroklimatycznej, jak i w skali topoklimatycznej. Prędkość oraz kierunek wiatru jest więc z reguły konsekwencją przestrzennego rozkładu pola ciśnienia nad danym makroregionem, może jednak podlegać odchyleniom w zależności od czynników lokalnych. Najważniejszymi czynnikami lokalnymi są konfiguracja i pokrycie terenu. Konfiguracja terenu modyfikuje parametry wiatru, wymuszając zmiany intensywności i kierunku przepływu. Pokrycie terenu zmienia wartość siły tarcia, czego konsekwencją jest zmiana prędkości wiatru. Zróżnicowane fizyczne właściwości podłoża wiążą się także z odmiennym bilansem energetycznym, warunkują bowiem albedo i zdolność pochłaniania promieniowania słonecznego. To z kolei decyduje o zróżnicowanej termice i wykształceniu lokalnych pól ciśnienia, które mogą 
zmieniać parametry wiatru wynikające z cyrkulacji makroskalowej. Wpływ lokalnych cech fizjograficznych terenu ujawnia się najbardziej podczas pogody radiacyjnej (małe zachmurzenie, niewielkie prędkości wiatru), kiedy przy dużej insolacji pojawia się największe zróżnicowanie termiczne w skali topoklimatycznej, co inicjuje lokalną cyrkulację powietrza. Na obszarach nadmorskich, gdzie występują obok siebie przynajmniej dwie zdecydowanie odmienne powierzchnie czynne morze i ląd, lokalna cyrkulacja powietrza $\mathrm{z}$ reguły wyraża się modyfikacją kierunku wiatru związaną z występowaniem bryzy oraz zmniejszeniem prędkości wiatru w miarę postępowania w głąb lądu, wynikającym $\mathrm{z}$ większego tarcia nad powierzchnią lądową, szczególnie pokrytą wysoką szatą roślinną.

Zagadnieniem występowania bryz lub efektu bryzowego na polskim wybrzeżu Bałtyku zajmował się Michalczewski (1967), który oszacował częstość występowania tego typu lokalnej cyrkulacji na 25 przypadków w ciagu roku, oraz Kwiecień (1974), która zauważyła bryzowe odchylenia kierunku wiatru w godzinach południowych. Bogucki (1994) szczegółowo opracował dobową zmienność kierunku wiatru na Mierzei Łebskiej w sezonie letnim, potwierdzając występowanie efektu bryzowego. Tamulewicz (2001) przedstawił prędkość wiatru w sezonie letnim na tym samym obszarze.

W niniejszym opracowaniu podjęto próbę wychwycenia lokalnych różnic prędkości wiatru na Mierzei Łebskiej w strefie przymorskiej nad wybranymi powierzchniami czynnymi oraz zidentyfikowania dobowej zmienności parametrów wiatru i cech cyrkulacji bryzowej. Piaszczyste i suche obszary Mierzei Łebskiej, częściowo pokryte roślinnością wydmową, częściowo lasem sosnowym, o bardzo charakterystycznych cechach topoklimatycznych, stanowią duży kontrast względem zbiorników wodnych Bałtyku i rozległego Jeziora Łebskiego. Stwarzają specyficzne warunki dla rozwoju lokalnej cyrkulacji atmosfery.

\section{METODY I ZAKRES BADAŃ}

Badania wykorzystane w niniejszym opracowaniu przeprowadzono od 1 lipca do 26 sierpnia 2009 r. w rejonie stacji terenowej Zakładu Klimatologii UAM na terenie Słowińskiego Parku Narodowego. Stacja położona jest w połowie długości Mierzei Łebskiej, 10 km na zachód od Łeby, w odległości kilkudziesięciu metrów od morza.

Składające się na charakter podłoża cechy fizjograficzne (topograficzne, geomorfologiczne i pokrycie roślinnością) zmieniają się na obszarze Mierzei Łebskiej pasowo, równolegle do wybrzeża. Najbliżej brzegu morskiego rozciagga się pas piaszczystej plaży, miejscami zasiedlony przez rośliny halofilne. Drugą równoległą do wybrzeża strefę w sensie geomorfologicznym stanowi 
wał wydmy przedniej kilkumetrowej wysokości. Pas ten pod względem pokrycia roślinnością określa się jako wydmę białą - piaszczysta, miejscami umocnioną wysokimi trawami (Piotrowska 1997). Za wałem wydmy przedniej występuje strefa obniżeń o innym pokryciu i barwie. Występują tu porosty, niskie trawy i turzyce, tworzy się zaczątek gleby z bardzo cienka warstwą próchnicy. Ze względu na swą barwę zespół ten nazywany jest wydmą szarą. Kolejną strefę stanowi nadmorski bór bażynowy, a na jego zapleczu rozciagają się wydmy ruchome.

Pomiary prędkości i kierunku wiatru, uzupełnione pełnym spektrum pomiarów meteorologicznych, wykonywano na dwóch stanowiskach pomiarowych, reprezentujących dwie z wymienionych stref morfologiczno-roślinnych:

1) piaszczysty szczyt wydmy przedniej, w odległości około $80 \mathrm{~m}$ od brzegu morskiego, wysokość bezwzględnej około $6 \mathrm{~m}$ (na podstawie pomiarów Królewicza i Kaczmarka (2008)); miernik wyniesiony na 1,5 m n.p.g., razem wysokość pomiaru 7,5 m n.p.m.,

2) las (nadmorski bór bażynowy) o wysokości koron powyżej $10 \mathrm{~m}$, punkt pomiarowy usytuowany $350 \mathrm{~m}$ od brzegu morskiego na wysokości $3,5 \mathrm{~m}$ n.p.m. (miernik 1,5 m n.p.g.), razem wysokość pomiaru 4 m n.p.m.

Pomocniczo wykorzystano stanowisko na wydmie szarej, w obniżeniu za wydmą przednią, w odległości około $100 \mathrm{~m}$ od brzegu morskiego, na wysokości $2 \mathrm{~m}$ n.p.g., miernik na statywie $4 \mathrm{~m}$ n.p.g., razem wysokość pomiaru $6 \mathrm{~m}$ n.p.m.

Do całodobowych cogodzinnych pomiarów wykorzystano zamocowane na statywach automatyczne mierniki meteorologiczne Kestrel-4500 (stanowisko 1. i 2.) oraz przenośną automatyczną staję meteorologiczną MAWS 201 (Vaisala) umieszczoną na wydmie szarej. Z 57 dób pomiarowych 25 sklasyfikowano na podstawie danych meteorologicznych jako radiacyjne.

\section{WYNIKI}

W lipcu i sierpniu 2009 r. nad Europą przeważała cyrkulacja zachodnia i południowo-zachodnia wywołana przez układy cyklonalne na północy kontynentu lub nad środkową Europą. Pojawiające się okresowo nad kontynentem układy antycyklonalne powodowały wschodnią lub północno-wschodnią cyrkulację, a wyże ulokowane nad środkową Europa powodowały sytuacje bezadwekcyjne. Układy antycyklonalne zapewniały z reguły pogodę radiacyjną o małym zachmurzeniu i niewielkiej prędkości wiatru.

W całym okresie pomiarowym (1.07-26.08.2009) zidentyfikowano $25 \mathrm{dni}$ z pogodą o charakterze radiacyjnym. Scharakteryzowano średnie warunki pogodowe dla całego okresu i dla dni radiacyjnych. Dla doby średniej całkowite promieniowanie Słońca wynosiło od $0 \mathrm{~W} \cdot \mathrm{m}^{-2} \mathrm{w}$ godzinach nocnych $(21.00-06.00)$ 
do ponad $500 \mathrm{~W} \cdot \mathrm{m}^{-2} \mathrm{w}$ godzinach $12.00-15.00$. Dni z pogodą radiacyjną charakteryzowały się większymi maksymalnymi wartościami promieniowania całkowitego (ponad $600 \mathrm{~W} \cdot \mathrm{m}^{-2}$ ).

Temperatura powietrza $\mathrm{w}$ badanym okresie osiagała minimum około godziny 4.00 (średnio $15,1^{\circ} \mathrm{C}$ ). Najwyższe temperatury (średnio $21,0^{\circ} \mathrm{C}$ ) notowano między godziną 14.00 a 15.00 . Średnia dobowa amplituda wynosiła $5,9^{\circ} \mathrm{C}$ (ryc. 1). Dni z pogodą radiacyjną charakteryzowały się większą amplitudą dobową $\left(7,5^{\circ} \mathrm{C}\right)$ wynikającą $\mathrm{z}$ wyższych wartości temperatury powietrza $\mathrm{w}$ godzinach około południowych (średnio $22,8^{\circ} \mathrm{C}$ o godzinie 14.00).

Wilgotność średnio wahała się od poniżej $70 \% \mathrm{w}$ godzinach popołudniowych do około $88 \%$ w godzinach nocnych. Niższe popołudniowe minima wilgotności względnej notowano w dniach z pogodą radiacyjną (około 66\%).

Ogólnie w okresie pomiarowym przeważały wiatry o niezbyt dużej prędkości - słabe $\left(2,1-5,0 \mathrm{~m} \cdot \mathrm{s}^{-1}\right)$ i bardzo słabe $\left(\right.$ do $\left.2 \mathrm{~m} \cdot \mathrm{s}^{-1}\right)$ według klasyfikacji Bartnickiego (1930). Mniejszy udział miały wiatry umiarkowane $\left(5,1-10,0 \mathrm{~m} \cdot \mathrm{s}^{-1}\right)$, rzadko, i tylko na stanowisku 1 , notowano wiatry silne $\left(10,1-15,0 \mathrm{~m} \cdot \mathrm{s}^{-1}\right)$.

Prędkość wiatru w ciagu doby charakteryzuje się wyraźną cyklicznością tak dla doby średniej z całego okresu pomiarowego, jak i dla dni z pogodą radiacyjną (ryc. 2). Minimalne prędkości wiatru na wydmie przedniej (1) notowano zwykle w godzinach wieczornych (22.00), po czym siła wiatru stabilizowała się do godziny 5.00, a następnie rozpoczynał się stopniowy wzrost prędkości

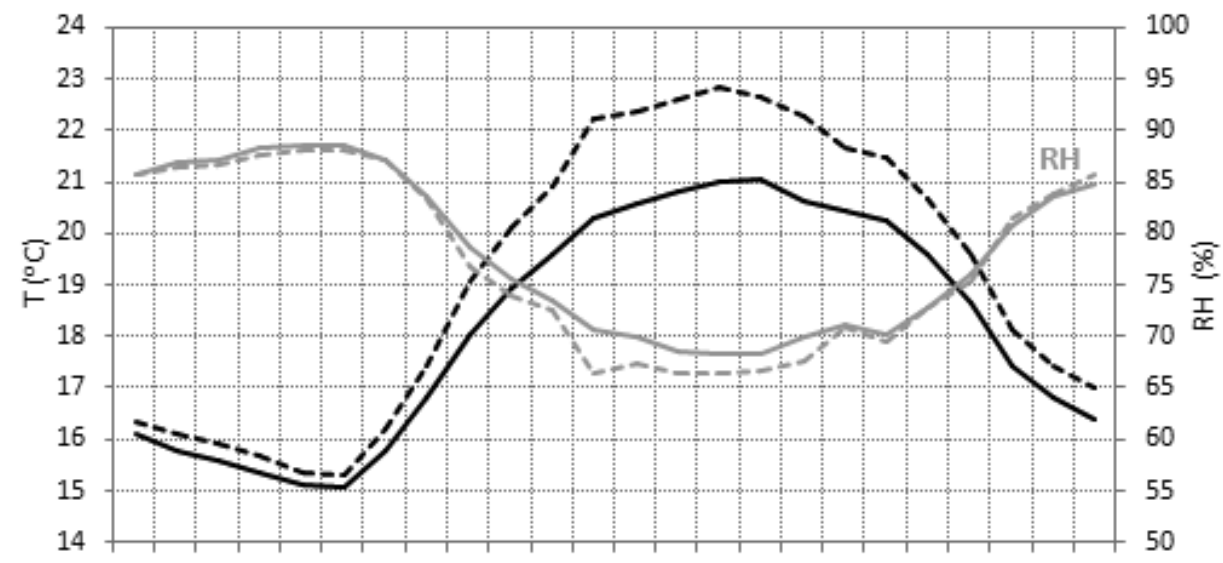

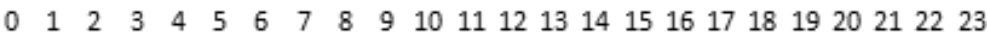

Ryc. 1. Dobowy przebieg temperatury powietrza $\left[T \mathrm{w}{ }^{\circ} \mathrm{C}\right] \mathrm{i}$ wilgotności względnej $[R H \mathrm{w} \%]$ dla wszystkich dni pomiarowych (linie ciągłe) i dób radiacyjnych (linie przerywane) na stanowisku 2

(wydma szara)

Fig. 1. Daily course of air temperature $\left(T\right.$ in $\left.{ }^{\circ} \mathrm{C}\right)$ and relative humidity $(R H$ in \%) for all measurement days (solid lines) and for radiation days (dashed lines) at the second post (grey dune) 
wiatru. Maksymalne wartości występowały w godzinach popołudniowych (między 13.00 a 15.00). W lesie panowały dużo mniejsze prędkości wiatru (ryc. 2 i tab.), z zachowaniem podobnego rytmu dobowego.

Stwierdzono znaczne różnice w dobowym przebiegu prędkości i kierunku wiatru pomiędzy stanowiskami. Zdecydowanie większe prędkości zanotowano na odsłoniętym stanowisku 1. (wydma przednia), które jest usytuowane najbliżej morza i na względnie dużej wysokości. Wyraża się to wartościami średnimi dobowymi oraz maksymalnymi zanotowanymi w czasie pomiarowym (tab., ryc. 2). Wiatr osiagał średnią prędkość około $4 \mathrm{~m} / \mathrm{s}$ w godzinach popołudniowych, kiedy występowały największe różnice w termice powierzchni czynnych, co intensyfikuje cyrkulację powietrza. Wtedy też z reguły w godzinach popołudniowych notowano największe chwilowe prędkości przekraczające $10 \mathrm{~m} \cdot \mathrm{s}^{-1}$, absolutne maksimum wynosiło14,7 $\mathrm{m} \cdot \mathrm{s}^{-1}$. Średnie minimalne prędkości $\left(<2 \mathrm{~m} \cdot \mathrm{s}^{-1}\right)$ wyliczono dla godzin wieczornych (22.00) i nocnych (23.00-4.00, około 2,3 $\mathrm{m} \cdot \mathrm{s}^{-1}$ ), kiedy wymiana energii na wszystkich powierzchniach czynnych słabnie i maleje gradient baryczny. W czasie dni radiacyjnych, $\mathrm{z}$ definicji charakteryzujących się mniejszymi prędkościami wiatru, średnia dobowa prędkość wiatru była obniżona, a maksymalne prędkości w godzinach popołudniowych dochodziły do $3 \mathrm{~m} \cdot \mathrm{s}^{-1}$. Minimalne prędkości wiatru w godzinach nocnych spadały poniżej $2 \mathrm{~m} \cdot \mathrm{s}^{-1}$.

Tabela. Prędkości wiatru $\left[\mathrm{m} \cdot \mathrm{s}^{-1}\right]$ na dwóch stanowiskach pomiarowych

Table. Wind speed $\left[\mathrm{m} \cdot \mathrm{s}^{-1}\right]$ at two measurement points

\begin{tabular}{cccccc}
\hline $\begin{array}{c}\text { Stanowisko } \\
\text { pomiarowe } \\
\begin{array}{c}\text { Measurement } \\
\text { point }\end{array}\end{array}$ & $\begin{array}{c}\text { Średnia dobowa } \\
\text { Daily average }\end{array}$ & $\begin{array}{c}\text { Maksymalna } \\
\text { średnia } \\
\text { dobowa } \\
\text { Maximum daily } \\
\text { average }\end{array}$ & $\begin{array}{c}\text { Minimalna } \\
\text { średnia } \\
\text { dobowa } \\
\text { Minimum daily } \\
\text { average }\end{array}$ & $\begin{array}{c}\text { Absolutne } \\
\text { maksimum } \\
\text { Absolute } \\
\text { maximum }\end{array}$ \\
$\begin{array}{c}\text { Wydma przednia } \\
\text { Frontal dune }\end{array}$ & 2,8 & 2,1 & 10,2 & 1,2 & 14,7 \\
$\begin{array}{c}\text { Las } \\
\text { Forest }\end{array}$ & 0,2 & 0,2 & 0,6 & 0,0 & 3,4 \\
\hline
\end{tabular}

A - wszystkie dni pomiarowe - all days of measurements, $\mathrm{R}$ - dni radiacyjne - radiation days

$\mathrm{Na}$ stanowisku usytuowanym w lesie (2) notowane były zdecydowanie mniejsze prędkości wiatru (tab., ryc. 2). Średnia prędkość wiatru wynosiła $0,2 \mathrm{~m} \cdot \mathrm{s}^{-1}$, tak w czasie dób radiacyjnych, jak i pozostałych. Średnia maksymalna prędkość wiatru w lesie przy każdej pogodzie osiagała maksimum równe około $0,5 \mathrm{~m} \cdot \mathrm{s}^{-1} \mathrm{~W}$ godzinach od 11.00 do 17.00 . Notowano nieliczne przypadki powiewów wiatru $\mathrm{w}$ lesie powyżej $2 \mathrm{~m} \cdot \mathrm{s}^{-1}$, a maksymalna zanotowana wartość wynosiła $3,4 \mathrm{~m} \cdot \mathrm{s}^{-1}$. Średnie minimalne wartości w godzinach nocnych 


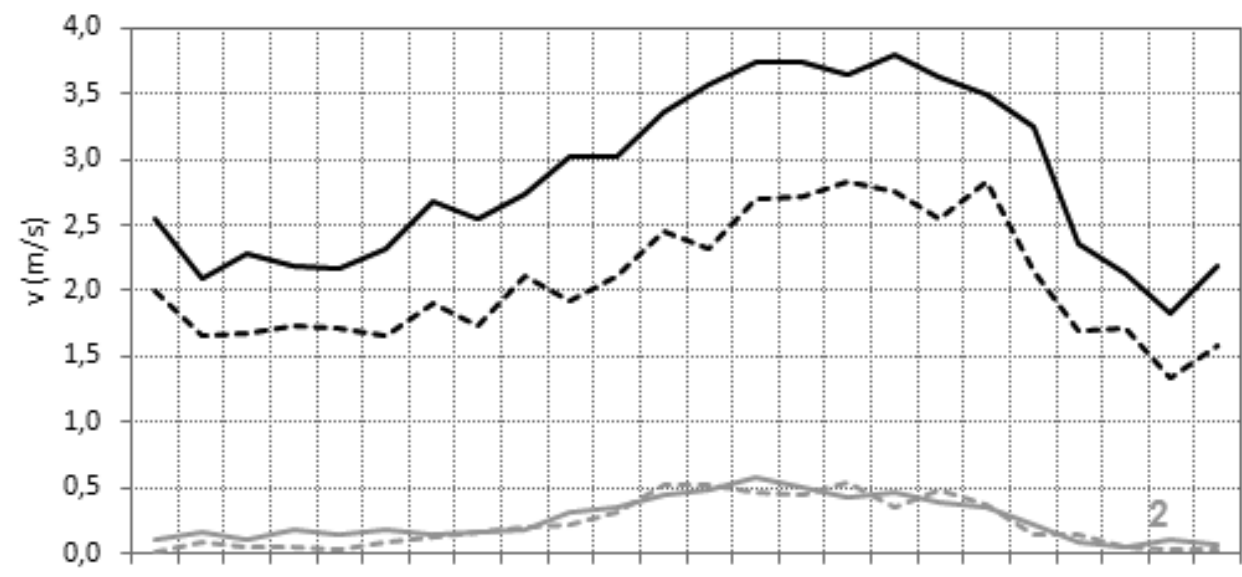

$\begin{array}{llllllllllllllllllllllll}0 & 1 & 2 & 3 & 4 & 5 & 6 & 7 & 8 & 9 & 10 & 11 & 12 & 13 & 14 & 15 & 16 & 17 & 18 & 19 & 20 & 21 & 22 & 23\end{array}$

Ryc. 2. Dobowy przebieg prędkości wiatru $\left[\mathrm{m} \cdot \mathrm{s}^{-1}\right]$ na wydmie przedniej (1)

i w lesie (2) dla wszystkich dni pomiarowych (linie ciągłe) i dób radiacyjnych (linie przerywane)

Fig. 2. Daily course of wind speed $(\mathrm{m} / \mathrm{s})$ at the frontal dune (1) and in the forest (2) for all measurement days (solid lines) and for radiation days (dashed lines)

(21.00-4.00) są bliskie zera. Przy tak małych prędkościach nie zanotowano istotnych różnic $\mathrm{w}$ dobowym przebiegu prędkości wiatru w czasie pogody radiacyjnej i ogółem.

Relacje pomiędzy prędkością wiatru na wydmie przedniej i w lesie przedstawiono za pomocą ryciny 3 .

Skalę redukcji prędkości wiatru w miarę przesuwania się od morza w głąb lądu określa równanie linii trendu dopasowanej do punktów na wykresie. Prędkość wiatru na stanowisku w głębi lasu jest średnio 20-krotnie mniejsza niż na położonej blisko morza i wyniesionej na wysokość kilku metrów wydmie przedniej. Znaczna redukcja prędkości wiatru wynika z:

1) pokrycia terenu - wysoki (ponad $10 \mathrm{~m}$ ) bór sosnowy o dużej szorstkości wydatnie hamuje ruch powietrza,

2) konfiguracji terenu - stanowisko w lesie znajduje się w obniżeniu za wydma przednią i kolejnymi wałami wydmowymi na niewielkiej wysokości bezwzględnej,

3) oddalenia od morza, gdzie wiatr z reguły nabiera większej prędkości dzięki małej szorstkości powierzchni wodnych.

Przeanalizowano rozkład dobowy częstości wiatrów z poszczególnych kierunków zmierzonych przez automatyczną staję meteorologiczną ulokowaną na wydmie szarej. Kierunek wiatru odpowiadał makroskalowej cyrkulacji atmosfery i w niewielkim stopniu podlegał wpływom warunków lokalnych. Przez cały 


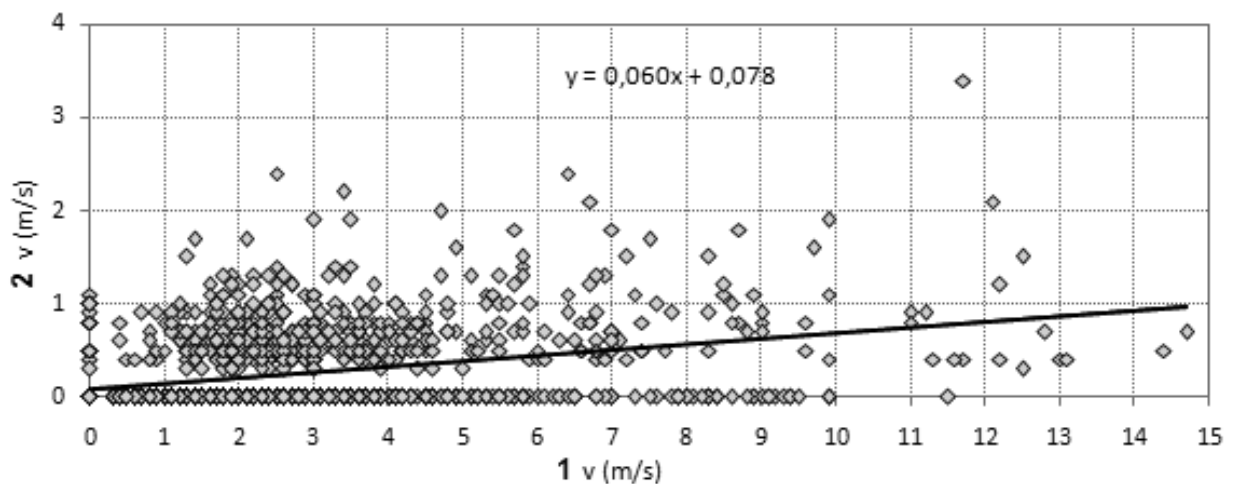

Ryc. 3. Zależność pomiędzy prędkością wiatru na stanowisku pierwszym wydma przednia (1) a prędkością wiatru na stanowisku drugim - las (2). Podano równanie modelu liniowego

Fig. 3. The relationship between wind speed at the first post -

frontal dune (1) and wind speed at the second post - forest (2). Equation of the linear model is given

okres pomiarowy dominowały wiatry z sektora zachodniego (ryc. 4), jednak pogoda radiacyjna związana była $\mathrm{z}$ występującą okresowo cyrkulacją wschodnią (ryc. 5). Kierunki z sektora południowego są liczniej reprezentowane w godzinach nocnych, natomiast sektor północny z największą częstością pojawia się w godzinach popołudniowych i wieczornych. Takie odchylenia kierunku wiatru wynikającego z warunków mikroskalowych znamionują wpływ lokalnej cyrkulacji o charakterze bryzowym.

\section{WNIOSKI}

$\mathrm{Na}$ podstawie krótkiego cyklu pomiarowego stwierdzono pewne cechy wspólne, ale także wyraźne różnice w dobowym przebiegu prędkości i kierunku wiatru na wybranych stanowiskach. W obu punktach pomiarowych potwierdziła się zasada dobowego cyklu zmian prędkości wiatru z największymi wartościami w godzinach popołudniowych i najmniejszymi w godzinach nocnych. Rytm ten jest najbardziej wyrazisty - z dużą amplitudą zmian - przy dużych prędkościach wiatru.

Prędkość wiatru słabnie w miarę odsuwania się od morza. Kilkusetmetrowa różnica odległości od morza, gdzie wiatr z reguły nabiera większej prędkości dzięki małej szorstkości powierzchni wodnych, pomiędzy stanowiskiem 1. (wydma przednia) i 2. (las) przełożyła się na około 20-krotny spadek prędkości wiatru. Znaczna redukcja prędkości wiatru wynika także z pokrycia terenu wysokim (ponad $10 \mathrm{~m}$ ) borem sosnowym o dużej szorstkości, która wydatnie hamuje ruch 


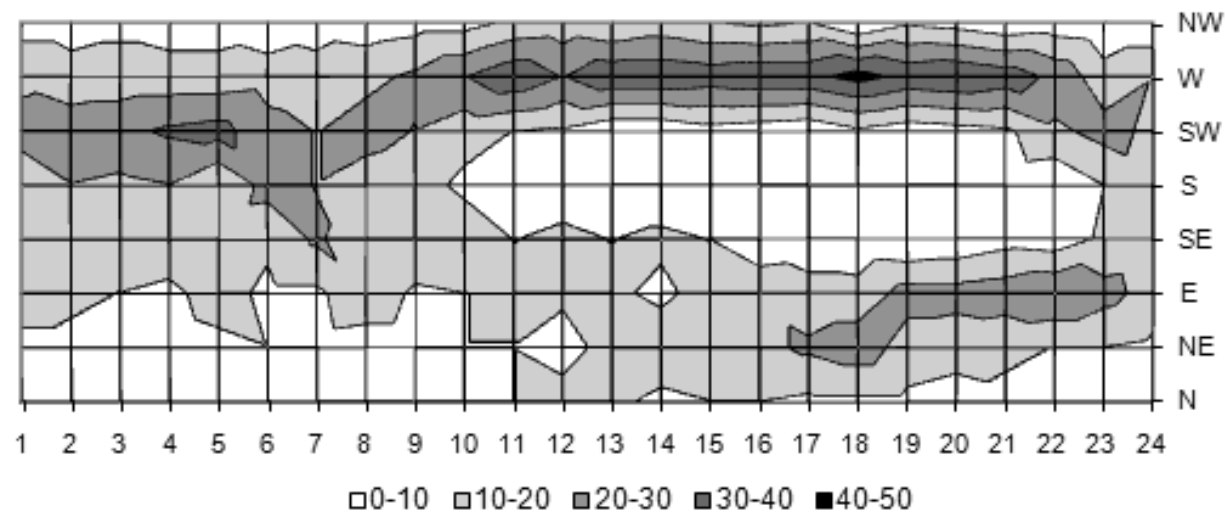

Ryc. 4. Izoplety dobowej zmienności kierunku wiatru na wydmie szarej (automatyczna stacja meteorologiczna MAWS) dla wszystkich dni pomiarowych. Udział poszczególnych kierunków wiatru w procentach

Fig. 4. Isopleths of the daily changes in wind direction at the grey dune (automatic meteorological station) for all days of measurements. Share of particular wind directions in percent

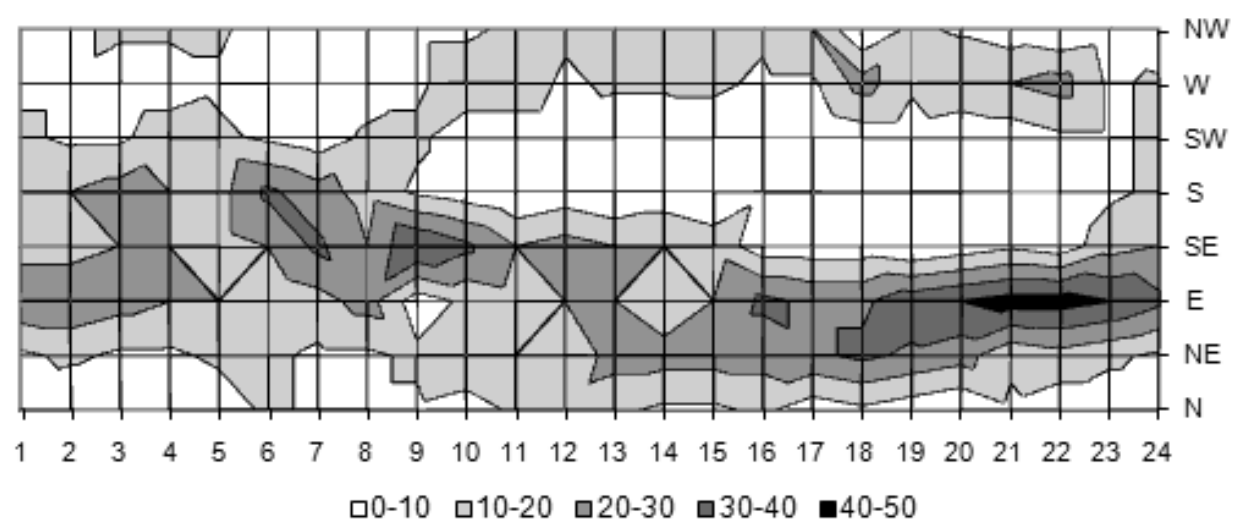

Ryc. 5. Izoplety dobowej zmienności kierunku wiatru na wydmie szarej (automatyczna stacja meteorologiczna MAWS) dla dni radiacyjnych. Udział poszczególnych kierunków wiatru w procentach

Fig. 5. Isopleths of the daily changes in wind direction at the grey dune (automatic meteorological station) for the radiation days. Share of particular wind directions in percent 
powietrza i konfiguracji terenu - stanowisko w lesie znajduje się w obniżeniu za wydma przednią i kolejnymi wałami wydmowymi na niewielkiej wysokości bezwzględnej. Ponadto, Rabski (1986) thumaczy mniejsze prędkości wiatru nad Mierzeją Łebską nasiloną konwekcją nad obszarem wydm ruchomych.

Typowa dla obszarów nadmorskich cyrkulacja bryzowa była na terenie badań słabo nasilona $\mathrm{w}$ okresie pomiarowym, przy wyraźnie dominującej makroskalowej cyrkulacji zachodniej. Objawiła się wpływem bryzy nocnej z południowym odchyleniem kierunku wiatru i bryzy dziennej z północnym odchyleniem kierunków wiatru. W literaturze dotyczącej polskiego wybrzeża Bałtyku więcej uwagi poświęca się bryzie dziennej, uznając bryzę nocna za rzadko występującą. Bogucki (1994) dokumentuje równą częstość bryzy lądowej i morskiej na Mierzei Łebskiej.

Wyniki przedstawione w niniejszej pracy należy uznać za wstępne ze względu na krótki okres pomiarowy i ograniczony zasięg przestrzenny. Jednak zróżnicowanie, jakie zaobserwowano na trzech wybranych stanowiskach, wskazuje, że warto kontynuować badania lokalnych zmian prędkości i kierunku wiatru na zróżnicowanym i specyficznym pod względem topoklimatycznym obszarze Mierzei Łebskiej.

\section{LITERATURA}

Bartnicki L., 1930: Prady powietrzne dolne w Polsce. Pr. Geofiz., 3, 98 s.

Bogucki J., 1994: Dobowa zmienność kierunku wiatru na Mierzei Łebskiej. Bad. Fizjogr. nad Pol. Zach., Ser. A - Geogr. Fiz., 45, 6-24.

Królewicz S., Kaczmarek L., 2008: Zmienność rzeźby terenu w strefie brzegowej na wybranym odcinku Mierzei Lebskiej w latach 2001-2007. Bad. Fizjogr. nad Pol. Zach., Ser. A - Geogr. Fiz., 59, 105-120.

Kwiecień K., 1974: Anomalie anemometryczne w przymorskim regionie województwa gdańskiego. Pr. IMGW, 2, 85-128.

Michalczewski J. 1967: Synoptyczne studium bryz morskich polskiego wybrzeża Bałtyku. Mat. PIHM.

Piotrowska H. 1997: Przyroda Stowińskiego Parku Narodowego. Bogucki Wyd. Nauk. PoznańGdańsk.

Rabski K., 1986: Elementy lokalnej cyrkulacji atmosfery oraz wielkości wybranych parametrów meteorologicznych na obszarze Mierzei Łebskiej. Pr. doktorska UAM, Poznań (maszynopis).

Tamulewicz J., 2001: Prędkość wiatru w sezonie letnim $w$ Stowińskim Parku Narodowym w obrębie Mierzei Łebskiej. Bad. Fizjogr. nad Pol. Zach., Ser. A - Geogr. Fiz., 52, 149-159. 